\title{
Keratosis pilaris and prevalence of acne vulgaris: a cross-sectional study*
}

\author{
Juliano Vilaverde Schmitt ${ }^{1}$ \\ Monique Carolina Meira do Rosário de Souza²
}

\author{
Brunno Zeni de Lima \\ Hélio Amante Miot ${ }^{1}$
}

DOI: http://dx.doi.org/10.1590/abd1806-4841.20142399

\begin{abstract}
BACKGROUND: Acne vulgaris has an important genetic predisposition, as well as keratosis pilaris. Clinical observations suggest that patients with keratosis pilaris have less frequent or less severe acne breakouts; however, we found no studies on this regard OвJестіvE: To determine if the presence of keratosis pilaris is associated with lower prevalence and severity of acne. METHODS: A cross-sectional study was conducted with dermatology outpatients aged between 14 and 35 years. We evaluated history and clinical grade of acne, demographic variables, history of atopy, smoking, and use of hormonal contraceptives. Two groups were defined by the presence or absence of moderate to severe keratosis pilaris on the arms and were compared by bivariate analysis and by conditional multiple logistic regression. Results: We included 158 patients (66\% women), with a median age of $23 \pm 11$ years. Twenty-six percent of them had keratosis pilaris, which was associated with a history of atopy (odds ratio $[\mathrm{OR}]=2.80[1.36$ to 5.75$] ; \mathrm{p}<0.01$ ). Acne was present in $66 \%$ of subjects, and was related to family history of acne ( $\mathrm{OR}=5.75$ [2.47 to 13.37]; $\mathrm{p}<0.01)$. In bivariate and multivariate analysis, the group with keratosis pilaris had a less frequent history of acne $(\mathrm{OR}=0.32$ [0.14 to 0.70]; $\mathrm{p}<0.01)$. ConCLUSION: The presence of moderate to severe keratosis pilaris on the arms was associated with lower prevalence of acne vulgaris and lower severity of facial lesions in adolescents and young adults.
\end{abstract}

Keywords: Acne vulgaris; Chromosomes, Keratosis; pair 18; Risk Factors; human

\section{INTRODUCTION}

Acne is a very common dermatosis, affecting $80 \%$ of adolescents and $40 \%$ of young adults. So far, it is believed that the tendency to develop it is based also on genetic factors that have not been clearly elucidated yet. ${ }^{1-6}$

Keratosis pilaris $(\mathrm{KP})$ is a frequent skin alteration characterized by the presence of follicular keratotic papules, associated or not with baseline erythema on the affected areas. KP can affect all skin surfaces where hair grows; however, it is more common on the proximal and extension regions of extremities and convex areas such as cheeks and buttocks. Similarly to acne, KP has a family tendency, and there have been reports of genetic syndromes, such as chromosome $18 \mathrm{p}$ deletion, which may manifest as prominent and extensive $\mathrm{KP}^{7-10}$
Acne and KP share many features, such as being dermatoses that affect the pilosebaceous follicles, with alterations in follicular keratinization, and showing a significant genetic trend..$^{4,5,7}$

Clinical observations performed by the authors of the present work suggest that patients with KP have less frequent and less severe acne breakouts, but no studies analyzing this hypothesis were found. This possible association may help in defining the prognosis of patients with acne, as well as provide new data for the study of both diseases.

The aim of this study was to investigate if the presence of KP on the upper limbs was associated with lower prevalence and lower severity of acne in adolescents and young adults.

Received on 04.01.2013.

Approved by the Advisory Board and accepted for publication on 27.01.2013.

* Study carried out at Hospital Universitário Evangélico de Curitiba - Faculdade Evangélica do Paraná (HUEC-FEPAR) - Curitiba (PR), Brasil

Financial Support: None

Conflict of Interest: None

PhD - Assistant Professor of the Department of Dermatology and Radiation Therapy of Faculdade de Medicina de Botucatu - Universidade Estadual Paulista "Júlio de Mesquita Filho" (FMB-UNESP) - Botucatu (SP), Brasil

Resident at the Dermatology service of Hospital Universitário Evangélico de Curitiba - Faculdade Evangélica do Paraná (HUEC-FEPAR) - Curitiba (PR), Brasil. 


\section{MATERIAL AND METHODS}

This cross-sectional study evaluated general dermatology outpatients aged between 14 and 35 years who spontaneously sought assistance from May to August 2011 and were selected by convenience sampling. Patients who had acne secondary to medications were excluded from the study, as well as patients who made use of oral isotretinoin or underwent dermatological procedures for the treatment of acne at any moment before the day of the interview, in order to preserve the reliability of the clinical grade of facial acne lesions.

The extensor surfaces of the arms were examined by standardized methods for the presence and intensity of alterations related to $\mathrm{KP}$, due to the fact that it is the most commonly affected region, and $\mathrm{KP}$ severity was subjectively graded as absent, mild, moderate, and severe (0 to 3 ), according to the density and intensity of follicular keratotic papules and of the associated erythema.

Patients were asked about personal and firstdegree family history of clinically significant acne (that motivated them to seek for medical treatment or left evident scars), current age, smoking, history of atopy, and family history of KP on the upper limbs. Women were also asked about the current use of hormonal contraceptives (HCs).

Patients were examined for the clinical grade of facial acne according to the classification proposed by the Food and Drug Administration (FDA) for clinical studies (Table 1). ${ }^{11}$

Categorical variables were represented by percentages, and associations were represented by odds ratio (OR) and 95\% confidence intervals. Continuous variables were represented by medians [interquartile deviations]. Data were compared by bivariate analysis using chi-square, Fisher's exact, and Mann-Whitney $\mathrm{U}$ tests. The Shapiro-Wilk test was used to determine the normality of distributions.

TABLE 1: Classification of acne severity based on the guidelines from the Food and Drug Administration for clinical studies.*

\begin{tabular}{ll}
\hline Clinical grade & Clinical characteristics of facial lesions \\
0 & No acne lesions \\
I & Rare blackheads and up to one papule or pustule \\
II & Some inflammatory lesions but no nodules \\
III & Many blackheads, some papules and pustules \\
& and up to one small nodule \\
IV & Many papules and pustules and several nodules
\end{tabular}

* US Department of Health and Human Services Food and Drug Administration Center for Drug Evaluation and Research (CDER). Guidance for Industry; AcneVulgaris: Developing Drugs for Treatment (2005).
In bivariate and multivariate analyses by multiple logistic regression, the dependent variable was the presence of moderate to severe KP on the upper limbs. The independent variables of adjustment were age, sex, personal history of atopy, family history of acne, and current use of HCs. Main independent variables were personal history of acne that motivated the patient to seek for medical treatment and the presence of inflammatory acne lesions on dermatological examination.

Minimum sample size was defined as 120 subjects to meet the criteria for exploratory multivariate analysis by multiple logistic regression with up to 10 independent variables.

A p-value $<0.05$ was set as significant.

\section{RESULTS}

A total of 158 patients with a median age of 23 [11] years were examined, $66 \%$ of which were women.

Twenty-six percent of the respondents had moderate to severe $\mathrm{KP}$, and all of these reported the presence of this alteration since childhood. There was an association between the presence of KP and personal history of atopy, even after adjustment for sex and age using multiple logistic regression $(\mathrm{OR}=2.99$ [1.48 to 6.60]; $\mathrm{p}<0.01)$. The association between $\mathrm{KP}$ and asthma was the most prominent among the atopic manifestations ( $\mathrm{OR}=3.46$ [1.33 to 9.04]; $\mathrm{p}=0.02)$.

Sixty-six percent of the subjects had or had already had clinically significant acne, showing an association with family history of acne (OR=5.75 [2.47 to 13.37]; $\mathrm{p}<0.01$ ).

The most frequent reasons for consultation were acne, $\mathrm{KP}$, seborrheic dermatitis, melasma, and atopic dermatitis (AD) (64.6\% of the total).

Table 2 shows the study variables according to two groups defined by the absence or presence of moderate to severe $\mathrm{KP}$ on the upper limbs. It is important to highlight the differences observed in history of acne and atopy between the groups.

The intensity of KP was inversely correlated with the current clinical grade of acne $(\mathrm{p}<0.01)$.

In the multivariate analysis by conditional multiple logistic regression adjusted for sex, age, history of atopy, use of HCs, and family history of acne, personal history of acne and the presence of inflammatory lesions on examination were less frequent in patients with moderate to severe $\mathrm{KP}(\mathrm{OR}=0.32$ [0.14 to $0.70] ; \mathrm{p}<0.01$ and $\mathrm{OR}=0.22$ [0.08 to 0.61$] ; \mathrm{p}<0.01$ ).

\section{DISCUSSION}

$\mathrm{KP}$ is a skin condition with a varied spectrum of intensity of presentation, usually starting at the first or second decades of life. It has a familial pattern of involvement, as shown by our data, with an autosomal dominant inheritance pattern. ${ }^{7,8}$ 
TABLE 2: Bivariate comparisons between the study variables, divided into patients with and without moderate to severe keratosis pilaris on the arms $(n=158)$.

\begin{tabular}{|c|c|c|c|c|}
\hline Variable & $\begin{array}{l}\text { Moderate to severe } \\
\text { keratosis pilaris } \\
\text { n (\%) }\end{array}$ & $\begin{array}{l}\text { Absent to mild } \\
\text { keratosis pilaris } \\
\text { n ( } \%)\end{array}$ & $\begin{array}{l}\text { Odds ratio ( } 95 \% \\
\text { confidence interval) }\end{array}$ & $\mathrm{p}$ \\
\hline \multirow[t]{2}{*}{ Sex* } & $17(36.2)$ & $37(33.3)$ & $1.13(0.56$ to 2,31$)$ & 0.73 \\
\hline & $30(63.8)$ & $74(66.7)$ & - & - \\
\hline \multirow{2}{*}{$\begin{array}{l}\text { Current age (years) } \\
\text { Personal history of acne } \\
(<25 \text { years of current age })^{* * *}\end{array}$} & $26[13]$ & $22[9]$ & - & 0.13 \\
\hline & $13(56.5)$ & $56(82.4)$ & 0.16 (0.04 to 0.58$)$ & 0.01 \\
\hline $\begin{array}{l}\text { Personal history of acne } \\
(>=25 \text { years of current age })^{\star * *}\end{array}$ & $6(25.0)$ & $29(67.4)$ & $0.16(0.05$ to 0.49$)$ & $<0.01$ \\
\hline $\begin{array}{l}\text { Use of hormonal } \\
\text { contraceptives (women) }{ }^{* * *}\end{array}$ & $15(50.0)$ & $42(56.2)$ & 0.78 (0.33 to 1.83$)$ & 0.57 \\
\hline \multirow{2}{*}{$\begin{array}{l}\text { Current smoking } \\
\text { Personal history of atopy } \\
\text { (atopic dermatitis, ashtma, } \\
\text { or allergic rhinitis)* }\end{array}$} & $5(10.6)$ & $11(9.9)$ & $1.08(0.35$ to 3.31$)$ & 0.99 \\
\hline & $32(68.1)$ & $48(43.2)$ & $2.80(1.36$ to 5.75$)$ & $<0.01$ \\
\hline \multirow{3}{*}{$\begin{array}{l}\text { Family history of acne } \\
\text { Family history of keratosis } \\
\text { pilaris on the upper limbs* }\end{array}$} & $8(17.0)$ & $52(46.9)$ & 0.23 (0.10 to 0.54$)$ & $<0.01$ \\
\hline & $30(63.8)$ & $20(18.0)$ & 8.03 (3.73 to 17.29$)$ & $<0.01$ \\
\hline & Clinic & ade of facial acne ${ }^{\dagger}$ & & \\
\hline \multirow{2}{*}{$\begin{array}{l}\text { No acne lesions } \\
\text { Grade I (Rare blackheads } \\
\text { and up to one papule } \\
\text { or pustule) }\end{array}$} & $32(68.1)$ & $35(31.5)$ & 1.00 (Reference) & $<0.01$ \\
\hline & $9(19.2)$ & $19(17.1)$ & $0.52(0.21$ to 1.31$)$ & - \\
\hline $\begin{array}{l}\text { Grade II (Some } \\
\text { inflammatory lesion } \\
\text { but no nodules) }\end{array}$ & $5(10.6)$ & $43(38.7)$ & 0.13 (0.04 to 0.36$)$ & - \\
\hline $\begin{array}{l}\text { Grades III-IV (Several } \\
\text { papules and pustules } \\
\text { and at least one nodule) }\end{array}$ & $1(2.1)$ & $14(9.0)$ & 0.11 (0.01 to 0.90$)$ & - \\
\hline
\end{tabular}

* Chi-square test; ** Mann-Whitney test, data expressed as median [interquartile deviation] ; *** Exact Fisher's test; † Chi-square test for trend.

Its pathophysiology is based on the genetically determined follicular hyperkeratinization, and it is more frequently found in its mild forms in our population, being characterized by the presence of follicular hyperkeratotic papules associated or not with an erythematous base and usually affecting the extensor surfaces of arms and thighs., ${ }^{710}$

Some studies identified an association between $\mathrm{KP}$ and $\mathrm{AD}$, but this association seemed to be limited to atopic patients with ichthyosiform skin, not being associated with other groups of patients. Similarly to KP, the pathophysiology of AD is also based on keratinization disorders, as well as on immunological factors. ${ }^{12,13}$
Our data did not find an association between $\mathrm{KP}$ and personal history of $\mathrm{AD}$, but an independent association was observed with personal history of atopy in general, especially asthma, which is suggestive of a relationship between atopic respiratory diseases and skin alterations in keratinization and of a significant hereditary nature of these conditions. ${ }^{12,13}$

The presence of KP may indicate congenital differences in the pattern of follicular keratinization. Some authors found cases of KP associated with chromosome 18p deletion, which may be related to an alteration in the functioning of the LAMA1 gene located on this chromosome. LAMA1 codifies laminin alpha, 
which is present in cutaneous annexes and seems to be important in forming sebaceous glands. Nevertheless, this chromosomal region may have some genes that regulate follicular keratinization, and these genes may play a role in the pathophysiology and in the genetic susceptibility for the development of acne and $\mathrm{KP}^{10,11}$

An association was observed between mutations in the filaggrin gene and ichthyosis vulgaris, which in some cases also manifests as follicular hyperkeratosis. Additionally, filaggrin expression in the sebaceous gland seems to differ between individuals with normal skin and those with acne-prone skin. On the other hand, a recent study found that mutations in the filaggrin gene associated with a reduction in its expression did not demonstrate a positive effect against the development of acne. ${ }^{12,14,15}$

Similarly to KP, the genetic factor seems to be one of the determinant factors for acne vulgaris. Studies on twins have shown that genetic factors account for up to $81 \%$ of the clinical variance of the disease. Our data corroborate this finding, since they show a strong association between personal and family history of clinically significant acne in our study population. On the other hand, it is not possible to rule out environmental factors shared by families, such as eating habits and even skin bacterial flora, in addition to a possible memory bias. ${ }^{6}$

Recently, idiopathic acne has been studied in age subgroups, with 25 years being the most used borderline age to distinguish adolescent acne from adult acne. Such approach is motivated by the fact that researchers noted that there were clinical and possibly etiopathogenic differences in the acne presented by these age groups. Our data showed an inverse association between KP and history of acne vulgaris even when analyzing separately the subgroups of patients below and above 25 years of age, indicating an association both in adolescent acne and in young adult acne. In addition, according to recent epidemiological studies, the prevalence of acne complaints in young adults was above $40 \%$. $^{1-3,16}$
Smoking has been associated with some forms of acne, especially in adults with predominantly retentional lesions. Similarly, the regular use of some formulations of HCs has proven to be beneficial in the treatment of acne in women and female adolescents. Nevertheless, our data did not show any significant difference in the prevalence of smoking and use of HCs between the study groups, indicating that these variables play a minor role in the clinical differences in acne observed between patients with and without PK. ${ }^{17,18}$

According to our literature review, this is the first study to objectively find an independent inverse association between KP and acne. KP was associated with lower risk of acne and lower severity of lesions. On the other hand, it should be highlighted that the study has some methodological limitations, such as possible selection and memory biases, the non-pairing of groups, and the small sample size; however, the intensity of the association increases its value. Furthermore, the possible use of topical treatments by patients on their own, which is common in acne cases, and the natural regression of KP that occurs after adolescence in up to $35 \%$ of the patients would have had an impact only on the decrease in the association observed. $^{8}$

The pathophysiogenesis of acne vulgaris is based on some principles: sebaceous hypersecretion, hyperkeratosis of the follicular infundibulum, and bacterial colonization by Propionibacterium acnes. The lower occurrence of acne in patients with KP may be due to a lower sebaceous secretion or to a differentiated pattern of follicular keratinization determined by genetic factors such as those observed in the chromosome $18 p$ deletion syndrome. However, genetic and molecular studies are needed to better clarify this mechanism. ${ }^{4,5,9,10}$

\section{CONCLUSION}

The presence of moderate to severe KP on the upper limbs may be associated with lower prevalence of clinically significant acne and lower severity of disease in the adolescent and young adult population. 


\section{REFERENCES}

1. Dreno B, Poli F. Epidemiology of acne. Dermatology. 2003;206(1):7-10.

2. Collier CN, Harper JC, Cafardi JA, Cantrell WC, Wang W, Foster KW, et al. The prevalence of acne in adults 20 years and older. J Am Acad Dermatol. 2008;58:56-9.

3. Kligman AM. Postadolescent acne in women. Cutis. 1991;48:75-7.

4. Hassun KM. Acne: etiopathogenesis. An Bras Dermatol. 2000;75:7-15

5. Costa A, Alchorne MMA, Goldschmidt MCB. Etiopathogenic features of acne vulgaris. An Bras Dermatol. 2008:83:451-9.

6. Bataille V, Snieder H, MacGregor AJ, Sasieni P, Spector TD. The influence of genetics and environmental factors in the pathogenesis of acne: a twin study of acne in women. J Invest Dermatol. 2002;119:1317-22.

7. Hwang S, Schwartz RA. Keratosis pilaris: a common follicular hyperkeratosis. Cutis. 2008;82:177-80.

8. Poskitt L, Wilkinson JD. Natural history of keratosis pilaris. $\mathrm{Br} J$ Dermatol. 1994;130:711-3.

9. Zouboulis CC, Stratakis CA, Gollnick HP, Orfanos CE. Keratosis pilaris/ulerythema ophryogenes and 18p deletion: is it possible that the LAMA1 gene is involved? J Med Genet. 2001;38:127-8.

10. Carvalho CA, Carvalho AV, Kiss A, Paskulin G, Götze FM. Keratosis pilaris and ulerythema ophryogenes in a woman with monosomy of the short arm of chromosome 18. An Bras Dermatol. 2011;86:S42-5

11. Fda.gov [homepage on the Internet]. US Department of Health and Human Services Food and Drug Administration Center for Drug Evaluation and Research (CDER). Guidance for Industry; AcneVulgaris: Developing Drugs for Treatment (2005). [cited 2013 Jan 03] Available from: www.fda.gov/downloads/Drugs/GuidanceCompliance RegulatoryInformation/Guidances/UCM071292.pdf

12. Sandilands A, O'Regan GM, Liao H, Zhao Y, Terron-Kwiatkowski A, Watson RM, et al. Prevalent and rare mutations in the gene encoding filaggrin cause ichthyosis vulgaris and predispose individuals to atopic dermatitis. J Invest Dermatol. 2006;126:1770-5

13. Mevorah B, Marazzi A, Frenk E. The prevalence of accentuated palmoplantar markings and keratosis pilaris in atopic dermatitis, autosomal dominant ichthyosis and control dermatological patients. Br J Dermatol. 1985;112:679-85.

14. Kurokawa I, Mayer-da-Silva A, Gollnick H, Orfanos CE. Monoclonal antibody labeling for cytokeratins and filaggrin in the human pilosebaceous unit of normal, seborrhoeic and acne skin. J Invest Dermatol. 1988;91:566-71.

15. Chen H, Common JE, Haines RL, Balakrishnan A, Brown SJ, Goh CS, et al. Filaggrin null mutations are not a protective factor for acne vulgaris. $\mathrm{Br} J$ Dermatol. 2011;165:106-14.

16. Schmitt JV, Masuda PY, Miot HA. Acne in women: clinical patterns in different agegroups. An Bras Dermatol. 2009;84:349-54.

17. Capitanio B, Sinagra JL, Ottaviani M, Bordignon V, Amantea A, Picardo M. Acne and smoking. Dermatoendocrinol. 2009;1:129-35.

18. Rich P. Hormonal contraceptives for acne management. Cutis. 2008;81:13-8.
MAILING ADDRESS:

Juliano Vilaverde Schmitt

Av. Sete de Setembro, 4713 - Água Verde

80240-000 - Curitiba - PR

Brazil

E-mail: julivs@gmail.com

How to cite this article: Schmitt JV, Lima BZ, Souza MCMR, Miot HA. Keratosis pilaris and prevalence of acne vulgaris: a cross-sectional study. An Bras Dermatol. 2014;89(1):91-5. 